\title{
Gênero e programas e projetos especiais de combate à pobreza no campo nordestino: reflexões sobre a participação das mulheres no Projeto Dom Távora em Sergipe
}

\author{
Magaly Nunes de Gois ${ }^{1}$
}

\section{Resumo}

O Projeto de Desenvolvimento de Negócios Rurais para Pequenos Produtores/Projeto Dom Távora é o projeto especial em execução em alguns estados da região Nordeste, incluindo Sergipe. O Acordo de Empréstimo e o Manual de Operações determinam que as comunidades quilombolas, povos indígenas, jovens e mulheres têm prioridade de atendimento. As mulheres rurais organizadas em associações e cooperativas devem ter acesso as ações e recursos correspondendo a $30 \%$ das pessoas atendidas. O presente artigo discute, a partir de uma perspectiva de gênero, a inserção e participação das mulheres no Projeto Dom Távora com base nos resultados obtidos até março de 2020 a fim de verificar se os resultados estão contribuindo para a inserção das mulheres nas associações e cooperativas e para o acesso as ações e recursos, configurado pelo financiamento e implantação de Planos de Negócios pensados, executados e geridos pelas mulheres.

Palavras-chave: mulheres rurais; projeto Dom Távora; planos de investimentos produtivos.

Gender and special programs and projects to combat poverty in the northeastern countryside: reflections on the participation of women in the Dom Távora Project in Sergipe

\footnotetext{
1 PRONESE, Assistente Social e Doutora em Educação. E-mail: magalyngois@gmail.com.
}

GT 11 - Gênero, políticas de desenvolvimento e combate à pobreza 


\begin{abstract}
The Rural Business Development Project for Small Producers / Dom Távora Project is the special project underway in some states in the Northeast region, including Sergipe. The Loan Agreement and the Operations Manual determine that quilombola communities, indigenous peoples, youth and women are given priority in service. Rural women organized in associations and cooperatives must have access to actions and resources corresponding to $30 \%$ of the people served. This article discusses, from a gender perspective, the insertion and participation of women in the Dom Távora Project based on the results obtained until March 2020 in order to verify whether the results are contributing to the insertion of women in associations and cooperatives and for access to actions and resources, configured by the financing and implementation of Business Plans designed, executed and managed by women.
\end{abstract}

Keywords: rural women; Dom Távora project; productive investment plans.

\title{
Introdução
}

A partir da década de 1970, o Estado brasileiro marca sua presença no campo, através da criação e implementação de programas e projetos especiais de caráter nacional e regional a fim de combater e minimizar as desigualdades regionais históricas na realidade do Brasil, segundo o discurso do Estado e dos governos. Esses projetos e programas especiais fazem parte do pacote de intervenções sociais para dar conta da nova ordem social e econômica e enfrentar as expressões da questão social, que a cada década vem se agravando e no atual cenário traz em seu bojo: desemprego estrutural; ampliação do subemprego e da informalidade; uberização do trabalho; desmonte dos direitos sociais; precarização das condições de trabalho e de vida; ampliação das desigualdades econômicas, sociais, culturais e ambientais; agravamento da exclusão social e; exacerbação da pobreza e da extrema pobreza.

A década de 1970 inaugura a fase de hegemonia dos programas e projetos especiais financiados com recursos internacionais. Os anos de 1980 dão continuidade a essa lógica com a implantação do Projeto Nordeste, intervenção que serve de insumo para a formulação e 
implementação, a partir de 1995, de projetos de combate à pobreza rural, os denominados PCPRs. O Projeto de Desenvolvimento de Negócios Rurais para Pequenos Produtores/Projeto Dom Távora é o projeto especial em execução em alguns estados da região Nordeste, incluindo Sergipe.

Numa tentativa de reparar e possibilitar a inclusão e o acesso de toda população, incluído as mulheres, às políticas públicas, o Estado brasileiro implantou, a partir dos anos 80 do Século XX, uma série de legislações e um conjunto de intervenções públicas direcionadas as denominadas minorias sociais - negros/as, mulheres, jovens, comunidades tradicionais ${ }^{2}$ e povos indígenas -, fruto do processo de redemocratização do Brasil e da pressão dos movimentos sociais e sindicais.

As bandeiras de lutas das minorias sociais passaram a fazer parte, a partir dos anos 2000, dos discursos e das metas de organismos internacionais por meio da definição de estratégias e de condicionalidades que possibilitem a inclusão e o acesso das comunidades quilombolas, povos indígenas, jovens e mulheres as ações, serviços e recursos das intervenções sociais implementadas com recursos externos.

O PCPR II - $2^{a}$ fase (2009-2011) é o primeiro projeto especial direcionado ao campo que prioriza o financiamento de projetos oriundos dos grupos de mulheres. O Projeto Dom Távora também prevê prioridade de atendimento as mulheres rurais organizadas em

\footnotetext{
2 De acordo com o Decreto $n^{\circ} 6040 / 2007$, os povos e comunidades tradicionais são definidos como "grupos culturalmente diferenciados e que se reconhecem como tais, que possuem formas próprias de organização social, que ocupam e usam territórios e recursos naturais como condição para sua reprodução cultural, social, religiosa, ancestral e econômica, utilizando conhecimentos, inovações e práticas gerados e transmitidos por tradição". Entre os povos e comunidades tradicionais do Brasil estão quilombolas, ciganos, matriz africana, seringueiros, castanheiros, quebradeiras de cocode-babaçu, comunidades de fundo de pasto, faxinalenses, pescadores artesanais, marisqueiras, ribeirinhos, varjeiros, caiçaras, praieiros, sertanejos, jangadeiros, ciganos, açorianos, campeiros, varzanteiros, pantaneiros, caatingueiros, catadoras de mangabas entre outros (BRASIL, 2007).
} 
associações e cooperativas e para tanto determina que 30\% das pessoas atendidas sejam mulheres.

O presente artigo discute sobre a participação e inserção das mulheres em um projeto de combate à pobreza, o Projeto Dom Távora, com base nos resultados obtidos até março de 2020 a fim de verificar se as mulheres estão tendo acesso as ações e os recursos do Projeto por meio do financiamento de Planos de Investimentos Produtivos (PIP) concebidos e geridos por elas e da participação em ações de capacitação.

\section{As mulheres do campo e a luta por reconhecimento, visibilidade e igualdade de oportunidade e de direitos}

A desigualdade entre homens e mulheres é uma marca da maioria das sociedades, concebida como um produto natural, "reflexo da natureza diferenciada dos dois sexos e necessária para a sobrevivência e o progresso da espécie" (MIGUEL, 2014, p. 17).

Ao questionar e rejeitar essa concepção que submete as mulheres a situações de opressão e de exploração, as mulheres repensam sua condição e lugar na esfera privada/doméstica e no âmbito das relações familiares, pois a "a posição da mulher na esfera doméstica, nas relações afetivas e de cuidado, é vista como a origem de uma linguagem moral distinta e mesmo superior à moral masculina, vigente na esfera pública" (BIROLI, 2014, p. 36) e, na esfera pública, em particular no mundo do trabalho e nos espaços de poder considerando que "numa sociedade estruturada pela dominação masculina, a posição das mulheres não é apenas 'diferente' da dos homens. É uma posição marcada pela subalternidade. Mulheres possuem menos acesso às posições de poder e de controle dos bens materiais" (MIGUEL, 2014, p. 102).

Os questionamentos e rejeição da condição impostas às mulheres levam as mesmas a lutarem e a organizarem movimentos de mulheres contra a dominação, a discriminação, o preconceito, o não reconhecimento enquanto sujeito de direitos e a invisibilidade no que 
tange a participação nos espaços decisórios e suas efetivas contribuição nos processos produtivos geradores da riqueza. Desde o século XVIII, com a primeira onda do feminismo, as mulheres desenvolvem e/ou se envolvem em ações coletivas na busca de igualdade de direitos.

Nos séculos XX e XXI as mulheres conquistam espaços nas políticas públicas, se inserem nos conselhos de direitos de diversas políticas sociais; criam movimentos sociais e Organizações Não Governamentais (ONG) de mulheres e/ou inserem na pauta dos movimentos e ONG suas bandeiras de luta; realizam congressos, conferências internacionais, nacionais, estaduais e municipais que discutem sobre suas realidades, definem estratégias de concepção e de intervenção públicas que incorporem as bandeiras de lutas e os direitos das mulheres.

As lutas das mulheres do campo por melhores condições de vida e de trabalho incluem em seus repertórios o acesso aos meios de produção essenciais a produção e reprodução da vida no campo - terra, água, crédito, sementes equipamentos e máquinas agrícolas, alternativas de comercialização e de escoamento da produção, assessoria técnica, formação/capacitação - e aos direitos sociais, materializados pelo acesso a saúde, educação, habitação, trabalho, lazer, assistência social, previdência social, enfim, independente se são demandas especificas ou universais, o que se busca é a garantia dos direitos sociais.

As mulheres também lutam e se movimentam para que as políticas públicas sejam concebidas e implantadas considerando as características, especificidades, conhecimentos e sabedorias dos povos do campo, que sejam DO e NO campo.

Aliado a luta por condições de vida e de trabalho, as mulheres lutam pelo reconhecimento, visibilidade como sujeitos portadoras de direitos e por igualdade de oportunidade, bandeiras de lutas que passaram a fazer parte dos discursos e das metas de organismos internacionais e dos governos em suas três instâncias, por meio da 
definição de estratégias e de condicionalidades que viabilizam a inclusão e o acesso das mulheres as ações, serviços e recursos previstos nas políticas, programas e projetos públicos.

Com essa perspectiva, o Estado brasileiro criou órgãos de articulação, coordenação e execução de políticas específicas para mulheres, a exemplo da Secretaria de Políticas Públicas para Mulheres (SPPM) e das Coordenadorias Estaduais de Políticas para Mulheres (CPPM) e incluiu nas diversas políticas, programas e projetos sociais estratégias de inclusão e de acesso das mulheres urbanas e rurais aos serviços e recursos, como o PRONAF MULHER, Território de Gênero do Programa Nacional do Crédito Fundiário (PNCF), o direito a titularidade da terra nos programas de acesso à terra e o Projeto Dom Távora.

Ressalto que a inclusão das bandeiras de lutas e dos direitos das mulheres rurais na agenda pública deve-se a organização e politização das mesmas, mediatizadas via movimentos de mulheres do campo, a exemplo dos Movimentos das Mulheres Trabalhadoras Rurais (MMTR), Movimento da Mulher Camponesa (MMC) e da Marcha das Margaridas que se constituem caminhos e trilhas para o reconhecimento, a visibilidade e igualdade de oportunidade direitos. (GOIS, 2012; GOIS, 2013).

\section{A inserção das mulheres do campo no projeto Dom Távora em Sergipe}

O cotidiano dos povos do campo3, melhor dizendo, dos que vivem do trabalho, tem por marcas a histórica presença da pobreza, a ausência de políticas públicas, a precarização das condições de vida e de trabalho, a contenção dos movimentos sociais e sindicais por meio

\footnotetext{
${ }^{3} \mathrm{~A}$ identidade dos povos do campo comporta categorias sociais como posseiros, bóiasfrias, ribeirinhos, ilhéus, atingidos por barragens, assentados, acampados, arrendatários, pequenos proprietários ou colonos ou sitiantes - dependendo da região do Brasil em que estejam - caboclos dos faxinais, comunidades negras rurais, quilombolas e, também, as etnias indígenas (GOVERNO DO PARANÁ, 2006, p. 24-5).
} 
do braço armado - os aparelhos oficiais (as polícias civis e militares e as forças armadas) e não oficiais de repressão (os jagunços, os matadores de aluguel e as milícias) com intenso uso da violência contra trabalhadoras e trabalhadores, lideranças sociais e sindicais e apoiadores/as das lutas e movimentos e a presença do Estado por meio do agro-negócio, "da territorialização do capital no campo" (OLIVEIRA apud CAMPOS, 2011, p. 147).

Para Campos (2011, p. 109),

o agronegócio deve ser compreendido como uma complexa articulação de capitais direta e indiretamente vinculados com os processos produtivos agropecuários, que se consolida no contexto neoliberal sob a hegemonia de grupos multinacionais e que, em aliança com o latifúndio e o Estado, tem transformado o interior do Brasil em um locus privilegiado de acumulação capitalista, produzindo, simultaneamente, riqueza para poucos e pobreza para muitos e, por conseguinte, intensificando as múltiplas desigualdades socioespaciais.

Essas marcas são produtos do modelo de desenvolvimento adotado no Brasil desde a década de 30 do século XX que prioriza o espaço urbano, a industrialização e a produção agrícola para exportação, especialmente a monocultura de grãos (soja, milho, trigo) em detrimento das atividades agrárias e do espaço rural.

As atividade agrárias são aqui concebidas como as desenvolvidas pelos povos do campo na agri-cultura que tem por características: a policultura; a produção, prioritariamente, para o mercado externo; cultivo e criação onde predominam as espécies nativas e da cultura local; conservação e enriquecimento da diversidade biológica; trabalho familiar e geração de emprego; maior ênfase na produção, processamento e mercado locais/regionais; produção pulverizada (maior número de estabelecimentos e agricultoras/es), controle da terra, recursos e capital; unidades de produção menores, menor dependência de insumos, fontes externas de conhecimento, 
energia e crédito; maior auto-suficiência individual e da comunidade; ênfase prioritária em valores, conhecimentos e habilidades pessoais; maior cooperação; incorporação de produtos e processos naturais; utilização de métodos culturais para cuidar do solo; integração entre agricultura e pecuária; utilização de recursos renováveis e conservação de recursos não renováveis, dentre outras

O espaço rural dos povos do campo se configura como o lugar de resistência e luta pela terra como um bem de uso e de produção e reprodução da vida humana e da natureza; um campo com muita gente, casa, escola, trabalho familiar; reciprocidade e uma enorme riqueza cultural. Um território onde a agri-cultura é considerada um modo de vida e um negócio, cujo produto tem primeira e prioritariamente um valor de uso e o excedente passa a ter um valor de troca; uma agricultura que utiliza uma abordagem holística da produção e que, otimiza todas as partes do agroecossistema; uma agri-cultura que concebe o ser humano com parte e dependente da natureza porque a natureza é fonte de recursos e precisa ser cuidada e conservada para o bem do próprio ser humano; uma agri-cultura que inclui agricultoras e agricultores; uma agri-cultura que defende o consumo sustentável, um estilo de vida mais simples e o acesso equitativo a necessidades básicas.

Em tempos de ultraneoliberalismo, de exacerbação do apoio do Estado e do capital internacional ao agronegócio e de intensificação da violência do Estado contra os povos do campo, em particular os povos indígenas, comunidades quilombolas, assentadas/os e acampadas/os, além da pobreza, estes convivem com a extrema pobreza. As condições de pobreza e de extrema pobreza ${ }^{4}$ vividas pelos povos do campo é consequência da histórica exclusão dos pobres das políticas públicas e da priorização do econômico em detrimento do social.

\footnotetext{
4 Famílias em situação de pobreza: renda familiar mensal per capita de até $\mathrm{R} \$ 446,00$ ou de até US\$ 5,50/ dia; em extrema pobreza: renda familiar mensal per capita de até R\$ 154,00 ou de até US\$1,90/dia. Disponível em: www.agenciabrasil.ebc.com.br. Acesso em: 25 ago. 2020
} 
Com a intencionalidade de enfrentar, pelo menos no plano do discurso, a histórica conjuntura de desigualdade, exclusão e pobreza presentes no campo brasileiro e sergipano, os governos federal e estadual, seguindo orientação de organismos financeiros multilaterais, em particular o Banco Mundial - intelectual orgânico e financeiro do capital -, direciona, a partir dos anos 90 do século XX, suas ações para os que vivem na pobreza e na extrema pobreza por meio da formulação de programas e projetos especiais, tornando-se uma estratégia hegemônica de atuação do Estado no campo brasileiro e, em particular, no da região Nordeste, concebidos por Campos (2011) como políticas compensatórias ou 'focopolíticas' construídas para "compensar" as trabalhadoras e trabalhadores que sofrem com as políticas macroeconômicas. $\mathrm{O}$ caráter compensatório e focalistas desses programas e projetos não alteram a realidade de pobreza, de exclusão e de desigualdade presente na vida dos povos do campo porque, segundo Campo (2011, p. 80):

Esses programas não são executados no âmbito de uma política social ampla, preocupada em reduzir as desigualdades, são focalizadas, visando atingir os mais pobres entre os pobres, sem alterar a história assimetria na produção e distribuição das riquezas. Neste sentido, esses programas convivem em perfeita harmonia com as políticas neoliberais, que são as grandes responsáveis pela ampliação e intensificação da pobreza nas últimas décadas.

As ações implementadas - os programas e projetos -, têm por caraterísticas a focalização, a seletividade, as condicionalidades de acesso e a descentralização em contraposição a universalidade e equidade asseguradas na Constituição Federal vigente características que não contribuem ou contribuem muito pouco no enfrentamento da pobreza no campo, considerando que a mesma vem crescendo.

Ao final de 2017, o índice de pobreza rural no Brasil aumentou e 1,49 milhão de pessoas passaram viver só com R \$ 136 por mês. Na extrema pobreza apenas 40,4\% dos domicílios possuíam acesso simultâneo ao 
saneamento básico (abastecimento de água, rede de esgoto e coleta de lixo). Em 2019 esses já são mais que $63 \%$. Dados do IBGE mostram moradias sem banheiro de uso exclusivo; paredes externas construídas com materiais não duráveis; excesso de moradores; aluguel consumindo mais de 30\% dos ganhos $^{5}$.

Importa ressaltar que em função dessas características, os programas e projetos contribuem para: desresponsabilização do Estado para com a oferta de políticas, programas e projetos sociais; intensificação do envolvimento e inserção das organizações da classe trabalhadora na execução das intervenções sociais; distanciamento dessas organizações das lutas sociais e da defesa dos interesses e direitos das/os trabalhadoras/es; ampliação da participação do mercado na oferta de políticas, programas e projetos sociais; crescimento do denominado Terceiro Setor; intensificação da negação de direitos e da pobreza e desigualdade social no campo.

[...] No interior do país, por exemplo, o Estado se alia com o latifúndio e o agronegócio, contribuindo para a ampliação da concentração de riquezas e com o forma de compensar a população mais afetada intensifica as políticas assistenciais focalizadas. Nesta perspectiva, o estado contribui para a retroalimentação da pobreza mesmo implementando políticas que aliviam a miséria, pois em vez de combater as causa do empobrecimento é parceiro nas ações que viabilizam o processo de produção e reprodução da pobreza (CAMPOS, 2011, p. 24).

Dando continuidade à estratégia hegemônica de atuação no campo por meio de programas e projetos especiais frutos de acordos de empréstimos internacionais está em execução em cinco estados da região Nordeste - Ceará, Bahia, Paraíba, Piauí e Sergipe -, o Projeto de Desenvolvimento de Negócios Rurais para Pequenos Produtores, denominado em Sergipe de Projeto Dom Távora, fruto de uma parceria

${ }^{5}$ Disponível em: https:/ / www.noticiario.com.br/noticia.php?cod_noticia=11782. Acesso em: 25 ago. 2020. 
com o Fundo Internacional de Desenvolvimento Agrário (FIDA), com previsão de implementação no período de seis anos e de encerramento em 2021, e um investimento total de total é de US\$ 28,6 milhões, sendo US\$ 16 financiados pelo Fida e US\$12,6 pelo Estado. Importa ressaltar que "além das contribuições do Governo de Sergipe e do FIDA, se preveem aporte dos beneficiários num montante de aproximadamente US\$ 9,2 milhões" (SERGIPE, 2016, p. 4).

O aporte de recursos pelos povos do campo, por meio de associações e cooperativas é uma característica dos programas e projetos especiais direcionados à área rural brasileira e nordestina constituindose em uma condicionalidade de acesso aos ações e recursos ofertados desde a segunda metade dos anos de 1980, com a implantação do Projeto Nordeste.

O Dom Távora é coordenado pela Secretaria de Estado da Agricultura, Desenvolvimento Agrário e da Pesca (SEAGRI), por meio de uma Unidade Técnica (UTE) responsável pela análise dos Planos de Investimentos Produtivos (PIP), encaminhados pelos povos do campo, via associações e cooperativas, que residam nos municípios área de abrangência, ou seja, nos 15 municípios mais pobres, nove da região semiárida e cinco do Baixo São Francisco, regiões com baixos indicadores econômicos e sociais, localizados em quatro dois oito territórios sergipanos: Agreste Central, Baixo São Francisco, Centro Sul e Médio Sertão.

Tem como meta atender diretamente 12 mil famílias de trabalhadoras e trabalhadores rurais, com ou sem terra e cerca de $40 \mathrm{mil}$ pessoas que atendam aos critérios de elegibilidade: a) trabalhadoras e trabalhadores rurais elegíveis pelo PRONAF, que comprovem o enquadramento mediante a apresentação da Declaração de Aptidão (DAP) ou Número de Inscrição Social (NIS) ou Registro Geral da Pesca (RGP); b) jovens rurais de 16 a 29 anos, com prioridade para as mulheres, negros, quilombolas e índios; c) trabalhadoras rurais, com prioridade para as que são chefes de família; d) trabalhadoras e trabalhadores rurais que residam nos municípios de atuação do Projeto; 
d) explorem atividades agropecuárias e não-agropecuárias associadas aos arranjos produtivos priorizados ou de comprovada importância econômica e social; e) desenvolvem atividades produtivas em grupo, formalizado, executando ao menos uma atividade relevante de forma associativa, priorizando as comunidades tradicionais. (SERGIPE, 2016).

O Projeto Dom Távora tem por objetivos, segundo o Manual de Operação do Projeto (SERGIPE, 2016, p. 3-4):

contribuir para a redução da pobreza rural por meio da promoção de negócios rurais, agropecuários ou não, por pequenos produtores pobres; promover a participação competitiva dos pequenos produtores e de suas organizações econômicas nos mercados de insumos, produtos, serviços e de trabalho; favorecer o acesso dos beneficiários aos serviços de assistência técnica e extensão rural, à qualificação e aos investimentos financeiros, para o desenvolvimento de negócios rurais; capacitar produtores para gerir seus empreendimentos individuais e associativos, e contribuir para a criação e o fortalecimento das organizações de produção, da transformação e da comercialização formadas pela população pobre rural, para agregar valor aos seus produtos e serviços e; fortalecer as capacidades institucionais dos organismos públicos e privados, que propiciem os serviços necessários para o desenvolvimento técnico e comercial dos negócios rurais.

Com a intencionalidade de atingir as metas e os objetivos, o Projeto Dom Távora foi e é organizado em três Componentes: o Componente 1 denominado Desenvolvimento de Negócios Rurais tem por finalidade apoiar o desenvolvimento de negócios rurais agropecuários e não agropecuários por meio do financiamento não reembolsável de Planos de Investimentos Produtivos (PIP) que contribuam para geração sustentável de renda englobando $73 \%$ dos recursos; Desenvolvimento de Capacidades para os Negócios Rurais é o Componente 2 que tem por objetivo fortalecer as capacidades das organizações e povos do campo diretamente envolvidas nos Planos de Investimentos Produtivos, para tanto são destinados 16\% do montante 
dos recursos; Monitoramento, Avaliação e Gestão do Projeto constitui o Componente 3 que tem por atribuição assegurar o financiamento da estrutura organizacional do Projeto, portanto este componente é responsável por todo o investimento e custos operacionais da Unidade Estadual de Gestão do Projeto (UEGP) e das quatro Unidades Locais de Gestão do Projeto (ULGP) e pelo sistema de Monitoramento e Avaliação do Projeto com destinação de $11 \%$ dos recursos para a realização das ações de monitoramento, avaliação e gestão (SERGIPE, 2016; SERGIPE, 2019).

Seguindo a mesma lógica e estratégia dos programas e projetos de enfrentamento da pobreza, ou seja, a focalização, a seletividade e a condicionalidade de acesso, os jovens rurais, os grupos étnicos e mulheres chefes de famílias organizados/as em associações e cooperativas têm prioridade de atendimento nas ações de assistência técnica e de capacitação e nos Planos de Investimentos Produtos coletivos. As mulheres e os jovens devem constituir 30\% dos/as pessoas atendidas pelo Projeto Dom Távora.

A estratégia de desresponsabilização do Estado e consequente transferência de responsabilidades para as organizações da classe trabalhadora e o mercado também está presente no Programa Dom Távora, considerando que os povos do campo por intermédio das associações e cooperativas e empresas de assistência técnica pública Empresa de Desenvolvimento Agropecuário de Sergipe (EMDAGRO) e privadas devem apresentar proposta para Planos de Investimentos Produtivos coletivos que envolvam atividades agropecuárias com foco nas seguintes atividades: rizicultura, apicultura, criação e beneficiamento de peixe, camarão e ostra, avicultura, ovinocultura, caprinocultura, fruticultura e beneficiamento da mandioca e/ou planos para atividades não agropecuárias, como o artesanato e o turismo rural, até o limite de $\mathrm{R} \$$ 5.750,00 por família.

Até março de 2020 foram financiados 154 Planos de Investimentos Produtivos contemplando 224 atividades produtivas, considerando que cada plano contempla até três atividades produtivas 
e 154 associações ou cooperativas. As principais atividades produtivas são: ovinocaprinocultura com 93 planos que correspondem a $41 \%$ do total de planos; a avicultura com 47 planos que representam $21 \%$; o artesanato e confecções com 17 planos correspondendo a 8\%; aquicultura e pesca com 17 planos representando 8\%; turismo de base com 5 planos que correspondem a $2 \%$; e as demais atividades com 45 planos englobando $20 \%$ das atividades produtivas contempladas.

O projeto desembolsou 99\% dos recursos oriundos do FIDA, ou seja do Acordo de Empréstimo, e hoje alcança a marca de 9.856 famílias beneficiadas por meio de Planos de Investimentos Produtivos (PIP) e de ações de capacitação e formação técnica operacional, previstas no Componente 2 - Desenvolvimento de Capacidades para os Negócios Rurais, alcançando $99 \%$ da meta pactuada e $82 \%$ do total de beneficiários/as, que é de 12.000 famílias.

Em relação ao Componente 1 - Desenvolvimento de Negócios Rurais, das 192 organizações de produtores rurais previstas para serem atendidas com o financiamento Planos de Investimentos Produtivos, o projeto atendeu a 154 associações e cooperativas atingindo $80 \%$ da meta, e atendeu 6.056 famílias, correspondendo a $98 \%$ da meta de beneficiar 6.200 produtores com recursos financeiros para investimentos produtivos.

No que tange a estratégia de focalização, materializada pela priorização de atendimento aos Planos de Investimentos Produtivos que contemplem mulheres, jovens e comunidades quilombolas, o Projeto dando atenção considerando que os 154 planos financiados atenderam 2.974 mulheres, correspondendo a 120\% da meta; 1.545 jovens representando $83 \%$ da meta; e 575 famílias quilombolas, número que corresponde a $184 \%$ da meta estabelecida no Acordo de Empréstimos e pela inserção em eventos de capacitação e de formação técnica e operacional direcionados a formação sócio-política, execução e gestão produtiva e coletiva, e a operacionalização técnica dos Planos financiados. 
De acordo com o relatório Desenvolvendo Capacidades (SERGIPE, 2019), até maio de 2019 foram realizados 169 eventos formativos com participação de 5.262 pessoas: 37 seminários sobre Associativismo e Cooperativismo; 77 cursos de Gestão de Negócios Agrícolas e Não Agrícolas, sendo um exclusivamente para técnicos; 42 oficinas de Gestão da Produção; quatro Intercâmbios a Planos de Investimentos das cadeias produtivas de Ovinocaprinocultura de Leite, Turismo Rural, Avicultura Caipira e Rizicultura Orgânica; nove Encontros da Juventude Rural, de Mulheres e de Quilombolas. Estes eventos formativos contaram com a participação 2.789 mulheres, número que representa $53 \%$ dos participantes e é que está acima da meta prevista, 30\% de mulheres; $20 \%$ de jovens correspondendo a 1.052 pessoas com idades de 16 a 29 anos e; $4 \%$ de povos do campo oriundos de comunidades tradicionais, sendo $3 \%$ de comunidades quilombolas e $1 \%$ de pescadores ribeirinhos que vivem nas margens do rio São Francisco.

Ao atender as demandas das mulheres por meio de financiamento de Planos de Investimentos Produtivos concebidos e geridos por elas e/ou de Planos com uma presença significativa de mulheres na condição de trabalhadoras usuárias das ações do Projeto, o Projeto Dom Távora vem construindo um caminho que pode contribui para o fortalecimento das lutas das mulheres por: reconhecimento enquanto trabalhadora e responsável, tanto quanto os homens e em muitas situações mais dos que os homens ${ }^{6}$, pelas atividades produtivas geradoras da riqueza familiar e coletiva, pois apesar da mulher ser responsável por $45 \%$ da produção agrícola, segundo o Censo Agropecuário (BRASIL, 2006) seu trabalho e o produto dele não é reconhecido; visibilidade de suas atividades produtivas realizadas ao redor da casa - nos quintais -, e na roça, seja em terra própria, cedida ou arrendada ou na venda da força de trabalho; reflexão sobre os lugares/espaços impostos histórico e culturalmente aos homens e as

\footnotetext{
6 Famílias em que os companheiros têm alguma limitação física que o impede de trabalhar e os filhos são pequenos e as famílias de mulheres solos.
} 
mulheres, o público é dos homens de e domínio masculino e o privado é das mulheres e de domínio feminino e; enfrentamento e superação da divisão sexual do trabalho e a desigualdade de gênero no esfera privada e pública (CAVALCANTI; LIMA, 2016; CONTAG, 2019b; CONTAG, 2019c).

A divisão sexual do trabalho e as desigualdades de gênero nas famílias é um exemplo, as jornadas de trabalho e o tempo dedicado as mulheres aos afazeres domésticos espelham exatamente tais desigualdades. A sobrecarga de trabalho cumprida por elas, aos se responsabilizarem por suas famílias e exercerem outras atividades, além das domésticas e de cuidados, é exaustiva e revela a permanência das desigualdades de gênero [...] A desigualdades permeia as relações entre homens e mulheres em nosso país e se reflete na esfera privada (família), como nos espaços públicos (na política, no movimento sindical, nos partidos políticos, no trabalho, etc) (CONTAG, 2019a).

No campo a esfera/ espaço público é a roça e o roçado, os lugares de produção e do trabalho com valor de uso e de troca, portanto, o lugar de mando e de comando dos homens, o lugar em que o trabalho da mulher é ainda visto como ajuda. O espaço/esfera privado no campo é a casa e o quintal, lugares de reprodução social e da produção com valor de uso, o lugar de domínio da mulher em que as atividades, quando realizadas pelos homens, são concebidas como ajuda (CARNEIRO, 1981; CARNEIRO; TEIXEIRA, 2005).

De acordo com a divisão sexual do trabalho, aos homens é destinada a esfera produtiva, onde os trabalhos realizados são valorizados e remunerados (ou geradores de renda); e às mulheres é destinada a esfera reprodutiva, onde o trabalho realizado não gera renda e, portanto, não é valorizado. Tem dois princípios que organiza esta forma de divisão social do trabalho: o princípio da separação, que afirma que existem trabalhos de homens e trabalhos de mulheres; e o princípio de hierarquização, a partir do qual o trabalho do homem "vale" mais do que o 
trabalho de mulher [...] A divisão sexual do trabalho faz com que as atividades das mulheres sejam vistas como parte do seu papel de mãe, vinculadas ao trabalho doméstico e de cuidados, que inclui a produção no quintal, da horta, do pomar e de pequenos animais. Aquilo que é produzido nos quintais vai para o autoconsumo, prioritariamente, e o que sobra é comercializado. Mesmo gerando alguma renda, o fato desse trabalho ser considerado extensão do trabalho doméstico, faz com que ele não seja considerado produtivo e nem seja valorizado. Mas o trabalho na lavoura/roçado, esse sim, é tido como produtivo. O que se produz aí vai para o mercado, é comercializado, é pago. A roça é o lugar prioritário de trabalho dos homens. É ele quem recebe por esse trabalho e, portanto, é ele quem toma as decisões. Quando realizado pelas mulheres, esse trabalho é considerado apenas uma "ajuda", mesmo que elas cheguem à lavoura e saiam junto com seus maridos (CONTAG, 2019c, p. 8-9).

No tocante à representatividade feminina em associações e empreendimentos implantados com do recursos do Projeto Dom Távora por meio do financiamento de PIPs, as mulheres integram $49 \%$ do quadro de povos do campo atendidos, o que representa um avanço de cerca de 35\% em relação ao marco inicial, que era de aproximadamente $14 \%$. Em relação à diretoria das associações e cooperativas gestoras dos empreendimentos, as mulheres integram 63\% destas esferas, sendo 14\% em diretorias compostas exclusivamente por mulheres e $49 \%$ em diretorias mistas com participação de mulheres e homens. Em algumas associações que tem diretorias mistas as mulheres ocupam o cargo de tesoureira, cargo de poder e historicamente ocupado por homens.

Dentre o universo de PIPs financiados, alguns atenderam exclusivamente e/ou majoritariamente a mulheres, a exemplo de:

1. Plano de Investimento de Apoio a Caprinocultura, único em Sergipe, localizado na comunidade Cacimba Nova, município de Poço Verde, território Centro Sul, com envolvimento de 19 mulheres e sob a responsabilidade da Associação de 
Desenvolvimento Comunitário Padre Cícero, cuja presidência e tesouraria são assumidas por mulheres. Ressalto que no processo de implementação do empreendimento as mulheres criaram uma cooperativa, a UNICAPRI, para comercializar seus produtos.

2. Plano de Investimento de Diversificação do Artesanato, localizado na comunidade quilombola Caraíbas, município de Canhoba, Território Baixo São Francisco, concebido e gerido por 24 mulheres via Associação Dona Paqueza Piloto que tem em sua presidência uma mulher que também é a presidenta da Federação Estadual das Comunidades Quilombolas de Sergipe que representa as 37 comunidades remanescentes de quilombos existentes em Sergipe e reconhecidas pela Fundação Cultural Palmares7.

3. Plano de Investimento de Apoio ao Artesanato, localizado na comunidade Passagem, município de Neópolis, território BaixoSão Francisco, concebido e gerido pela Associação Artesanal Formiguinhas Em Ação e por 22 mulheres, incluindo a presidenta e tesoureira da associação, e dois homens que produzem peças artesanais com a folha da palmeira do Ouricuri.

Para o nome, nos inspiramos na fábula das formigas que trabalham cooperandouma com as outras noverão, para terem reserva de alimentos no invernos. Também tem a ver com a colheita/;no invernos não tem como fazer a secagem da palha. Por isso temos que fazer um estoque no verão, igual as formiguinhas [...] Dos 24 associados, dois são homens e cuidam da coleta das palhas, e22 são mulheres organizadas conformea expertise de cada uma. Quinze delas produzem artesanato de palha - com capacidade de quarenta peças por mês, enquanto duas pintam cem peças em tecido; No mesmo período, quatro mulheres trabalham o biscuit, originando cinquenta peças, mas bastam duas crocheteiras para cinquenta artigos e uma para cinquenta luminárias artesanais (FIDA, 2019a, p. 98-101).

7 Dados atualizados pela Fundação Cultural Palmares em 20 de julho de 2020. Disponível em: http://www.palmares.gov.br/wpcontent/uploads/2015/07/TABELA-DE-CRQ-COMPLETA-QUADRO-GERAL-20-072020.pdf. Acesso em: 29 agosto 2020. 
4. Plano de Investimento de Apoio ao Corte e Costura e ao Artesanato, localizado no povoado Nova Brasilia, município de Tobias Barreto, território Centro Sul, elaborado e gerido pela Associação das Bordadeiras e Moradores do Povoado Nova Brasilia que tem uma presidenta e uma tesoureira eatende a 60 pessoas, sendo 49 mulheres e 11 homens.

São diferenciais desse grupo a qualidade e a singularidade das peças, cuja produção é feita de forma coletiva e colaborativa cada peça passa pelas mãos de várias artesãs até chegar ao produto final. Outro diferencial importante é a participação de homens e mulheres jovens, exemplo de sucessão de trabalho e cultura para jovens do semiárido (FIDA, 2019b, p. 47).

5. Plano de Investimento de Apoio a Criação e Produção de Galinhas Caipiras, Codornas e Aquisição de Trator, implantado no Projeto de Assentamento Francisco José dos Santos, quem tem uma mulher na tesouraria, localizado na comunidade Malhadinha, município de Poço Verde, território Centro Sul, atendendo a 37 assentadas e assentados. O investimento possibilitou a resgate de sementes crioulas 8 - feijão de carioca, feijão-de-corda, fradinho, feijão branco, milho taquaral, milho raio de sol, milho catingueiro, melancia forrageira e palma forrageiras - a redução e até mesma a eliminação do usos de agrotóxicos e foi denominado pelas famílias assentadas de Integração Sementes e Liberdade porque têm a posse e propriedade de dois meios de produção - o trator e as sementes - para além da terra que já possui. "Liberdade quer dizer que temos sementes e trator pra plantar na época certa, sem precisar ir buscar fora ou depender do governo" (FIDA, 1019b, p. 95).

8 Variedades tradicionais melhoradas pelas comunidades camponesas do mundo inteiro, não possuindo restrição para sua multiplicação. Elas representam sementes e mudas de todas as plantas utilizadas, seja como alimento; uso medicinal ou ritual; alimentação animal; ou produção de fibra (têxtil). Geralmente estão sob cuidados de agricultores e guardiões de sementes. O processo de melhoramento genético aconteceu há aproximadamente 10.000 anos, quando mulheres faziam a seleção de sementes na natureza. Geração após geração, variedades que conhecemos hoje forma desenhadas (GOVERNO DO PARANÁ, s/d). 
6. Plano de investimento de apoio ao desenvolvimento da avicultura e de práticas agroecológicas, implantado na comunidade quilombola Mocambo, município de Aquidabã, território Médio Sertão sob a responsabilidade da Federação Estadual das Comunidades Quilombolas de Sergipe que têm na presidência e na tesouraria duas mulheres. Este empreendimento atende a 29 pessoas, mulheres e homens

A presença exclusiva e/ou majoritária de mulheres nesses Planos de Investimentos Produtivos aponta para a lideranças de mulheres em algumas comunidades rurais, incluindo comunidades remanescentes de quilombo, conquista das lutas e movimentos de mulheres por ocupação de espaços de poder, por igualdade de oportunidade nas políticas públicas, por reconhecimento de sua condição de trabalhadora, por visibilidade de sua capacidade de produção e dos frutos do seu trabalho e por autonomia econômica. Para a CONTAG (2019c, p. 21), autonomia econômica pode ser entendida como:

a capacidade das mulheres de gerar renda e recursos próprios a partir do seu próprio trabalho, em igualdade de condições com os homens, sendo essencial para que as mulheres possam prover seu próprio sustento e decidir por suas próprias vidas. Ela não envolve, portanto, apenas independência financeira e geração de renda, mas pressupõe também autonomia para realizar escolhas. $\mathrm{O}$ acesso aos mercados e à renda é parte necessária para que as mulheres tenham autonomia econômica. Mas a autonomia econômica vai além e envolve também o direito garantido aos serviços públicos - como saúde e educação - que no atual contexto de retirada de direitos é cada vez mais difícil e implica mais gastos. A autonomia econômica envolve também a capacidade de decidir sobre os tempos e os recursos e de colocar em prática essas decisões. Muitas vezes a resistência dos homens da comunidade é um obstáculo que as mulheres enfrentam para colocar em prática suas decisões (CONTAG, 2019b, p. 5). 
Sem dúvidas que a conquista da autonomia econômica é essencial para que as mulheres possam ser responsáveis pelos seus próprios sustentos e para compartilharem o sustento de suas famílias e das famílias de outras mulheres, para que façam escolhas e para decidir e para pôr em prática suas decisões (CONTAG, 2019c). As falas de algumas mulheres responsáveis pelos Planos de Investimentos destacados acima, afirmam a importância da busca pela autonomia econômica.

Eu acordo cedo, cuido da casa, preparo as crianças para a escola e vou trabalhar [...] Grande parte do material de construção de minha casa própria foi adquirida com a venda do artesanato e dos cursos de artesanato que dei [...] (Vice-presidenta da Associação Artesanal Formiguinhas em Ação apud FIDA, 2019a, p. 102).

Hoje eu tenho meu próprio plantio e posso dizer: colhi cinco sacos de feijão crioulo (Josélia Alves apud FIDA, 2019b, p. 97).

O projeto Dom Távora, motivou mais o espírito do associativismo como uma forma de aumentar nossa fonte de renda, pois aprendemos a analisar nossos pontos fortes e fracos e também como somos mais fortes e produtivas quando estamos unidas em torno de um único objetivo (Presidenta da Associação de Bordadeiras e Moradores do Povoado Nova Brasília apud FIDA, 2019b, p. 56).

Um dado que considero importante destacar é que as atividades produtivas contempladas pelos Planos de Investimentos Produtivos com presença exclusiva e/ou majoritárias de mulheres são atividades historicamente definidas no campo, como de mulheres porque são exercidas na esfera privada: no espaço interno e/ou no alpendre as mulheres produzem o artesanato e estocam as sementes crioulas, e no quintal criam e cuidam dos pequenos animais, a cabra, a galinha caipira e a codorna. A produção de sementes crioulas também é uma atividade com intensa participação das mulheres, as chamadas guardiãs de sementes, mulheres que lutam pela produção saudável de alimentos 
desde sua germinação e partilha as próprias sementes e os conhecimentos ancestrais que carregam.

Friso que essa característica dos PIPs não diminuem a importância dos mesmos na busca das mulheres por inserção nas políticas públicas, por autonomia econômica e pelo enfrentamento de seu lugar de inferioridade e de submissão ao homem, chefe de família, mesmo quando não assume a condição de provedor ou quando compartilha com a mulher a provisão da casa e da roça.

\section{Por fim, algumas considerações não finais}

As mulheres rurais vem empreendendo algumas lutas no sentido de serem reconhecidas como trabalhadora; de que seu trabalho e os frutos gerados por suas atividades produtivas, desenvolvidas no espaço/esfera público/a - na roça e no roçado -, e por suas atividades reprodutivas realizadas no espaço/esfera privado/a - na casa e no quintal - sejam vistas e respeitadas como atividades geradoras de renda e de riqueza; por igualdade de oportunidade e de direitos visto que todos os indicadores sociais e econômicas medidos por instituições governamentais e organismos internacionais não deixam dúvidas quanto a histórica existência de uma significativa desigualdade de gênero e quanto a permanência dessa desigualdade, materializada pelo acesso desigual aos serviços, benefícios e recursos das políticas pública, em particular, ao mundo do trabalho, pela predominância da pobreza nas famílias que tem a mulher como única provedoras, denominadas de famílias chefiadas por mulheres e /ou de mulheres solos e, pela injusta e desigual responsabilidade com as tarefas domésticas que impõem as mulheres duplas e triplas jornadas de trabalho.

Não podemos esquecer que a inserção da mulher na esfera pública por meio da entrada e ampliação da força de trabalho feminina no mercado de trabalho não significou compartilhamento de suas responsabilidades com as atividades da esfera privada, ou seja, com a reprodução da família. As tarefas da casa e do quintal ainda continuam 
sendo de responsabilidade, quase que exclusiva das mulheres e, quando o homem desenvolve algumas dessas tarefas, estas são vistas como ajuda. As tarefas da roça e do roçado são predominantemente dos homens, e quase como uma determinação natural, o trabalho realizado pelas mulheres na roça e no roçado ainda é visto como ajuda.

Apesar da persistência das desigualdades entre mulheres e homens - uma dimensão da desigualdade de gênero -, as lutas empreendidas pelas mulheres do campo tem provocado algumas conquistas lentas e graduais com alguns avanços e muitos retrocessos a partir de 2016, com o golpe político, jurídico e midiático, intensificados com a chegada de Bolsonaro e de alguns governadores ultraconservadores e ultra neoliberais ao poder, configurados por: a) criação de mecanismos que estão possibilitando romper com o silêncio, a valorização das tarefas e atividades desenvolvidas pelas mulheres na esfera privada e pública; b) reconhecimento pelos povos do campo da capacidade organizativa das mulheres, por meio da ocupação da presidência e tesouraria de associações comunitárias de comunidades de agricultoras e agricultores famílias, assentamentos de reforma agrária e comunidades quilombolas e da assunção a condição de gestoras de Planos de Investimentos Produtivos; c) acesso a informação e aos serviços, benefícios e recursos públicos, no caso específico do Projeto Dom Távora, contribuindo para a geração de renda e minimização da pobreza no contexto das famílias rurais atendidas e, d) assunção a condição de sujeitos de direitos, embora haja muito por construir em termos de políticas estruturantes e políticas públicas para as mulheres.

Por fim, as mais importantes conquistas das mulheres rurais, quando de sua participação nas políticas públicas, são chamar a atenção do Estado e da sociedade para sua existência, no sentido, segundo Gois (2012), de enfrentar e superar a condição excludente que lhes é imposta, apesar destas representarem $48 \%$ da população rural brasileira, 36\% da população rural economicamente ativa e pela produção de $30 \%$ dos alimentos básicos e de difundir valores e concepções sobre a vida rural 
em que há lugares tradicionalmente estabelecidos para homens e mulheres nas relações familiares e nas diferentes dimensões de seu cotidiano.

\section{Referências}

BIROLI, F. O público e o privado. In: MIGUEL, L. F.; BIROLI, F. Feminismo e Política: uma introdução. São Paulo: Boitempo, 2014. p. 3146.

BRASIL. Censo Agropecuário 2006. Rio de Janeiro: IBGE, 2006.

BRASIL. Constituição da República Federativa do Brasil. Brasília: Presidência da República, Casa Civil, 1988.

BRASIL. Decreto $n^{\circ}$ 6040/2007 - Institui a Política Nacional de Desenvolvimento Sustentável dos Povos e Comunidades Tradicionais. Brasília: Presidência da República, Casa Civil, 2007.

CAMPOS, C. S. S. A face feminina da pobreza em meio à riqueza do agronegócio: trabalho e pobreza das mulheres em territórios do agronegócio no Brasil: o caso de Cruz Alta/RS. Buenos Aires: CLACSO, 2011.

CARNEIRO, M. J. Ajuda e trabalho: a subordinação da mulher no campo. 1981. ANPOCS.

CARNEIRO, M. J.; TEIXEIRA, V. L. Mulher rural nos discursos dos mediadores. Revista Estudos Sociedade e Agricultura, 05, p. 45-57, 2005.

CAVALCANTI, M. P. de H.; LIMA, E. E. H. Tenório de. Marcha das Margaridas: participação política, empoderamento e movimento social em rede das mulheres do campo e da floresta. Aceno - Revista de Antropologia do Centro-Oeste, v. 3, n. 5, p. 94-107, jan./jul. 2016.

CONTAG. Cadernos de debates: desenvolvimento sustentável na perspectiva das mulheres do campo, da floresta e das águas. Caderno 1 - Margaridas na luta por um Brasil com soberania popular, democracia, justiça, igualdade e livre de violência, por democracia com igualdade e fortalecimento da participação política das mulheres. Brasília: Contag/Secretaria de Mulheres Trabalhadoras Rurais Agricultoras familiares. 2019a. 
CONTAG. Cadernos de debates: desenvolvimento sustentável na perspectiva das mulheres do campo, da floresta e das águas. Caderno 3 -Por autonomia econômica, trabalho e renda, por terra, água e agroecologia. Brasília: Contag/Secretaria de Mulheres Trabalhadoras Rurais Agricultoras familiares. 2019b.

CONTAG. Plataforma Política Marcha das Margaridas: por um Brasil com soberania popular, democracia, justiça e livre violência. Brasília: Contag/Secretaria de Mulheres Trabalhadoras Rurais Agricultoras familiares. 2019c.

FIDA. Mulheres que florescem o semiárido nordestino: histórias de produtoras apoiadas pelos projetos do FIDA no Brasil. Salvador: FIDA, 2019a.

FIDA. Riquezas do Semiárido: histórias de sucesso impulsionadas pelas ações do FIDA no Nordeste brasileiro. Salvador: FIDA, 2019a.

GOIS, M. N. de. A participação da sociedade civil nas políticas públicas: uma discussão sobre a operacionalização do Projeto de Combate à Pobreza Rural (PCPR II - $2^{\mathrm{a}}$ fase). 2010. 131f. . Monografia (Especialização em Serviço Social: Direitos Sociais e Competências Profissionais) - UFS Universidade de Brasília/Conselho Federal de Serviço Social, 2010.

GOIS, M. N. de. A Participação das Mulheres no Projeto de Combate à Pobreza Rural (PCPR II - $2^{\mathrm{a}}$ fase). Jornada Internacional de Políticas Públicas, VI., São Luís, 2013. Anais [...]. São Luís/MA: UFMA, 2013.

GOIS, M. N. Marcha das Margaridas: mulheres trabalhadoras rurais construindo igualdade de direitos, políticas públicas e cidadania. Seminário Latino Americano de Escuela de Trabajo Social, XX., 2012. Anais [...]. Argentina: ALAEITS, 2012. p. 1-12.

GOVERNO DO PARANÁ. Diretrizes Curriculares da Educação do Campo. Curitiba: Secretaria de Estado da Educação, 2006. Disponível em: <www.diaadiaeducacao.pr.gov.br>. Acesso em: 14 abr. 2016.

GOVERNO DO PARANÁ. Sementes crioulas: origem e importância. Pinhais: CPRAGROECOLOGIA, s/d. Disponível em: http:// www.cpra.pr.gov.br/arquivos/File/folderSementes.pdf. Acesso em: 29 ago. 2020. 
MIGUEL, L. F. Gênero e representação política. In: MIGUEL, L. F.; BIROLI, F. Feminismo e Política: uma introdução. São Paulo: Boitempo, 2014. p. 93-107.

MIGUEL, L. F. O feminismo e a política. In: MIGUEL, L. F.; BIROLI, F. Feminismo e Política: uma introdução. São Paulo: Boitempo, 2014. p. 1629.

SERGIPE. Desenvolvendo capacidades: uma experiência de fortalecimento institucional de organização da agricultura familiar em Sergipe. Sergipe: SEAGRI, 2019.

SERGIPE. Manual de operações do projeto (M.O.P) - Projeto de Desenvolvimento de Negócios Rurais para Pequenos Produtores - Dom Távora. Sergipe: SEAGRI, 2016. 